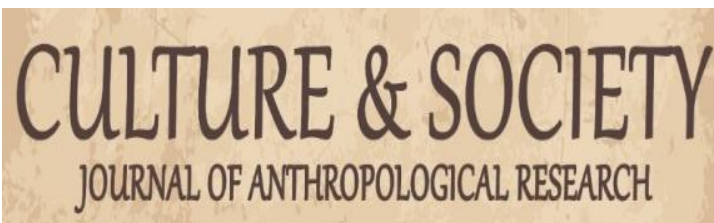

Culture \& Society: Journal of Anthropological Research

VOL. 2 NO. 4 JUNI 2021

http://culture.ppj.unp.ac.id

Email: culture@ppj.unp.ac.id

ISSN: 2686-343X (E-ISSN) 2686-3421 (P-ISSN)

DOI: https://doi.org/10.24036/csjar.v2i4.77

\title{
Bui Ibara Lagat Bagatta Samba Musara Lek Sita Kasimaeruk: Integrasi Sosial Beda Agama pada Masyarakat Mentawai
}

\author{
Ayu Puspita Sari ${ }^{1}$, Erda Fitriani ${ }^{2}$ \\ ${ }_{1,2}^{1}$ Universitas Negeri Padang \\ Email: pitas3801@gmail.com, fitriani_cim@fis.unp.ac.id
}

\begin{abstract}
Abstrak
Tujuan dari penelitian ini adalah menjelaskan dan mendeskripsikan penyebab masyarakat Mentawai mampu hidup rukun, walaupun di dalam satu keluarga ada perbedaan agama di Desa Mongan Poula Kecamatan Siberut Utara, Kepulauan Mentawai. Penelitian ini dilakukan dengan pendekatan kualitatif dengan tipe penelitian Etnografi. Teknik pemilihan informan penelitian ini yaitu Purposive Sampling (Sampel bertujuan). Pengumpulan data dilakukan dengan cara observasi partisipasi, wawancara mendalam, dan studi dokumen. Teknik analisis data dengan model analisis etnografi dari James Spradley. Data dianalisis melalui Teori Konflik Gluckman yang menyatakan bahwa antara konflik, moral, kepercayaan, agama atau ritual, dan mengatakan bahwa aspek-aspek kebudayaan inilah yang saling terjalin sehingga konflik yang terjadi dalam masyarakat tidak sampai menghancurkan sistem sosial. Berdasarkan hasil penelitian diperoleh informasi bahwa yang menjadi faktor utama masyarakat Mentawai khususnya Desa Mongan Poula mampu hidup rukun atau hidup bersama karena adanya nilai adat istiadat yang mengajarkan mereka sejak kecil hingga sekarang, seperti nilai Sitangiangalau dan nilai Pagetsabbau. Kedua nilai tersebut menjadi pemersatu antara roh-roh manusia dengan roh gaib yang menjalin kebersamaan mereka selalu hidup bersama. Nilai adat istiadat tersebut sangat makna bagi masyarakat Mentawai yaitu selalu hidup berdampingan dengan sesama mereka. Filosofi dari Simakerek bagatta, Puaranan Simaeruk dan Bui Ibara Laggat Bagtta Samba Musara Lek Sita Kasimaeruk memiliki makna integrasi sosial antara beda agama di Desa Mongan Poula. Nilai adat ini sangat kuat sekali tertanam dalam masyarakat Mentawai karena mereka menghargai masing-masing orang termasuk orang berbeda agama dan menghindari konflik. konflik yang ada di masyarakat dapat diselesaikan oleh tokoh adat yang disebut dengan pabalai.
\end{abstract}

Kata Kunci: Adat Istiadat, Integrasi sosial, Mentawai, Perbedaan agama.

\section{Abstract}

The purpose of this research is to explain and describe the reasons why the Mentawai people are able to live in harmony, even though within one family there are religious differences in Mongan Poula Village, North Siberut District, Mentawai Islands. This research was conducted with a qualitative approach with ethnographic research type. The technique of selecting the informants in this research is purposive sampling. The data was collected by means of participatory observation, in-depth interviews, and document study. The data analysis technique used the ethnographic analysis model from James Spradley. The data is analyzed through Gluckman's conflict theory which states that conflicts, morals, beliefs, religion or rituals, and says that these aspects of culture are intertwined so that conflicts that occur in society do not destroy the social system. Based on the results of the research, information was obtained that the main factor for the Mentawai people, especially Mongan Poula Village, was able to live in harmony or live together because of the values of customs that taught them from childhood until now, such as the value of Sitangiangalau and the value of Pagetsabbau. These two values unite the human spirits and the supernatural spirits who form together as they always live together. These traditional values are very meaningful to the Mentawai people, namely to always live side by side with their fellowmen. The philosophy of Simakerek Bagatta, Puaranan Simaeruk and Bui Ibara Laggat Bagtta Samba Musara Lek Sita Kasimaeruk has the meaning of social integration between different religions in Mongan Poula Village. This customary value is very strongly embedded in the Mentawai community because they respect each person, including people of different religions and avoid conflict. conflicts in the community can be resolved by traditional leaders known as pabalai.

Keywords: Customs, Mentawai, Religious differences, Social Integration.

\begin{tabular}{l|l|l} 
Received: May 2, 2021 & Revised: June 2, 2021 & Published: June 4, 2021
\end{tabular}

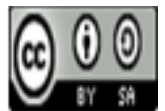

Culture \& Society: Journal of Anthropological Research Vol. 2, No. 4, Th. 2021 


\section{Pendahuluan}

Integrasi sosial merupakan penyatuan dari kelompok- kelompok yang tadinya terpisah satu sama lain dengan melenyapkan perbedan sosial dan kebudayaan yang ada sebelumnya. Integrasi sosial juga diartikan sebagai diterimanya seorang individu oleh anggota lain dari suatu kelompok. Kelompok sosial dapat terwujud atas dasar agama atau kepercayaan suku, ras, dan kelas. Dalam konteks ini integrasi tidak selamanya menghilangkan diferensiasi tetapi yang terpenting adalah memelihara kesadaran untuk menjaga keseimbangan hubungan (Syaifuddin 1986).

Integrasi sosial juga merupakan proses penyesuaian diantara unsur-unsur yang saling berbeda dalam kehidupan sosial, sehingga menghasilkan suatu pola kehidupan yang serasi bagi masyarakat tersebut. Integrasi sosial dapat terbentuk apabila para anggota masyarakat bersepakat mengenai struktur kemasyarakatan, nilai nilai dan norma serta pranata sosial yang berlaku dalam masyarakat tersebut dan diperlukan agar masyarakat tidak bubar meskipun menghadapi berbagai tantangan fisik maupun konflik yang terjadi secara sosial budaya (Muslich, 2013).

Di dalam suatu negara yang terdapat agama berbeda khususnya di Indonesia memiliki enam agama yang diakui dan tidak mudah untuk mempersatukan atau memperdamaikan seluruh masyarakat yang bertempat tinggal di negara Indonesia, tergantung dalam diri masing-masing individu bagaimana bersikap terhadap agama yang berbeda dengan kita (Harton, 1984). Berdasarkan ketentuan yang berlaku di Indonesia, terdapat beberapa agama yang diakui dan dijamin keberadaannya oleh pemerintah yaitu agama Islam, Kristen, Katolik, Hindu, Budha dan Kong $\mathrm{Hu} \mathrm{Chu}$. Perbedaan agama di satu sisi memang rawan karena menjadi benih perpecahan. Akan tetapi selama masing masing umat mau bersikap toleransi dan saling menghormati, maka persatuan dan kerukunan antar umat beragama bisa terjadi.

Dalam masyarakat majemuk Indonesia ini cenderung terjadi konflik antar masyarakat karena adanya perbedaan, dan terjadi karena satu tujuan di antara mereka tidak bisa tercapai. Masalah konflik dalam masyarakat majemuk tidak jarang menyangkut nilai-nilai dasar yang melandasi hubungan antara masyarakat yang mengedepankan prinsip kesetaraan antara budaya yang beragam. Secara sosiologis konflik diartikan sebagai proses sosial antara dua orang atau lebih serta kelompok, yang salah satu terjadi perpecahan (Abidin \& Yusuf, 2014).

Perbedaan ras, suku dan agama memang benar-benar bisa menjadi penyebab terjadinya perbedaan pendapat dan dapat mengarah pada terjadinya konflik. Oleh sebab itu, harus bisa menjaga persatuan agama agar tidak dapat menimbulkan konflik, apabila bisa menjaga kedamaian di negara Indonesia secara bersama saling menghormati segala perbedaan tidak hanya masalah agama tetapi juga masalah ras, suku dan lain sebagainya. Maka satu persatu konflik bisa tidak terjadi lagi tetapi yang seperti itu sangat sulit sekali untuk bisa menguranginya, hanya orang-orang atau kelompok tertentu yang bisa menjaga kedamaian.

Penelitian ini difokuskan kepada sekelompok masyarakat Desa Mongan Poula Kecamatan Siberut Utara Kabupaten Kepulauan Mentawai. Masyarakat desa ini dipilih sebagai subjek penelitian karena faktor masyarakat Desa Mongan Poula mampu hidup rukun, mereka menjalin silahturahmi dengan baik walaupun di dalam masyarakat bahkan di dalam satu keluarga terdapat perbedaan agama. Alasan peneliti memilih Desa Mongan Poula sebagai lokasi penelitian sebab di Desa tersebut tidak ditemukan konflik antar umat beda agama, adapun konflik yang terjadi biasanya tidak terkait agama. Adapun konflik konflik kecil tidak terkait dengan agama bisa diselesaikan secara damai dengan pimpinan tokoh adat yang disebut dengan Pabalai. Masyarakat juga memiliki falsafah atau pepatah adat dan masih diterapkan dalam diri mereka masing-masing orang Mentawai yaitu "Bui Ibara Langgat Bagatta Samba Musara lek Sita Kasimaeruk artinya jangan ada ada konflik diantara sesama marilah kita sama-sama membina dalam kerukunan atau kita adalah satu dan kita adalah keluarga.

Desa Mongan Poula merupakan salah satu contoh wilayah yang memiliki keberagaman. Keberagaman yang ada di desa ini adalah keberagaman agama. Agama yang berbeda dalam satu wilayah yang sama tentunya akan menimbulkan konflik. Desa Mongan Poula terdiri dari tiga

Culture \& Society: Journal of Anthropological Research Vol. 2, No. 4, Th. 2021 
dusun yaitu Dusun Selatan, Dusun Barat, dan Dusun timur. Masyarakat Desa Mongan Poula memiliki agama yang berbeda keyakinan yakni agama Islam, Khatolik, Krisen Protestan, IFGF (International full gospel fellowship atau gereja Injil seluruh Indonesia) dan Baha"I. Agama paling banyak dianut masyarakat Desa Mongan Poula adalah agama Katolik. Agama Katolik 75,20 persen, agama Islam 59,00 persen, agama Kristen Protestan 30,45 persen, agama Baha i 15,25 persen, dan agama IFGF 20,49 persen (data dari desa Mongan Poula tahun 2021). Menjadi suatu yang menarik untuk dikaji secara mendalam mengenai masyarakat Mentawai di desa ini, karena mereka dapat hidup harmonis dengan perbedaan agama di desanya.

Beberapa penelitian relevan dengan penelitian yang dilakukan yaitu penelitian yang dilakukan oleh Retno Wiyanti (Universitas Negeri Semarang UNES 2019) dalam skripsinya yang berjudul "Kerukunan Antarumat Beragama di Desa Gebangsari Kecamatan Klirong Kabupaten Kebumen" Fakultas ilmu sosial". Hasil penelitiannya adalah: interaksi antarumat beragama yakni dialog dan kerjasama, membalas kejahatan dengan kebaikan, peningkatan pendekatan wilayah, kerjasama sosial dan layanan kesehatan, kesenian, percaya pada agama sendiri dan menghargai agama orang lain, doa bersama, sikap pluralisme, budaya, dan pendidikan. Faktor yang melatarbelakanginya yakni pemahaman negara Indonesia sebagai negara plural, pemahaman pada ajaran agama masing-masing, dan pandangan hidup rukun. Sementara cara untuk menjaga kerukunan ditempuh dengan kesadaran bahwa manusia adalah makhluk sosial, saling menghormati dan menghargai satu sama lain, dan sosialisasi pemerintah Desa (Wijayanti, 2019).

Sedangkan penelitian yang dilakukan oleh Vita Sri Dwi Saputri (Institut Agama Islam Negeri Purwokerto (IAIN) 2019) dengan skrpsinya yang berjudul "interaksi sosial umat Islam dan umat Kristen Pantekosta di Desa Suro Kecamatan Kalibagor Kabupaten Banyumas". Fakultas Ushuluddin Adab dan Humaniora Jurusan Studi Agama". Hasil penelitian ini adalah bahwa bentuk interaksi sosial atar umat Islam dengan umat Kristen Pantekosta di Desa Suro membentuk interaksi sosial yang sosial yang mengarah pada kerja sama, Akomodasi dan Asimilasi antara umat Islam dan Kristen Pantekosta yang dilakukan dalam kehidupan sehari hari (Saputri, 2019).

Fenomena yang terkait kerukunan umat beragama sudah dilakukan penelitian sebelumnya, namun yang menjadi aspek kebaruan membedakan penelitian ini dengan penelitian yang sudah ada yakni mengkaji dimensi adat masyarakat Mongan Poula sehingga mampu hidup rukun.

\section{Metode Penelitian}

Penelitian ini dilakukan dengan pendekatan kualitatif (Sutomo, 2017). Penelitian kualitatif adalah membuka peluang bagi peneliti mendapatkan informasi yang yang lebih mendalam, ungkapan dan penuturan langsung dari masyarakat Desa Mongan Poula yang mengetahui selak beluk tentang nilai-nilai adat yang menyebabkan masyarakat Desa Mongan Poula mampu berintegrasi sosial beda agama. Tipe penelitian yang digunakan adalah tipe Etnografi yang dikemukakan oleh James Spradley.

Penelitian ini dilakukan di Desa Mongan Poula, Siberut Utara Kepulauan Mentawai. Lokasi ini dipilih karena di Desa tersebut kerukunan antar umat beragama sudah membudaya dari nenek moyang mereka dahulu dan sampai sekarang masih diterapkan. Konflik ada di masyarakat ini, akan tetapi tidak terkait dengan perbedaan agama dan dapat diselesaikan secara damai dengan pimpinan tokoh adat dan juga terdapat peraturan dari desa yang mengharuskan seluruh masyarakat Desa Mongan Poula untuk menjaga silahturahmi dengan baik sesama masyarakat.

Teknik pemilihan informan dengan cara Purposive Sampling (Sampel bertujuan). Informan penelitian adalah orang yang memberikan informasi dan kondisi yang berkaitan dengan masalah penelitian (Afrizal, 20016). Dalam penelitian ini informan berjumlah 20 orang diantaranya, 15 warga Mongan Poula, 2 orang Tokoh Adat, 1 Kepala Desa, 1 orang Ustadz, 1 orang Bajak Gereja (Ketua Gereja).

Culture \& Society: Journal of Anthropological Research Vol. 2, No. 4, Th. 2021 
Metode pengumpulan data yang digunakan adalah observasi partisipasi, wawancara mendalam, dan studi dokumentasi. Untuk mendapatkan keabsahan dan kebenaran data yang telah dikumpulkan maka peneliti perlu melakukan triangulasi data. Dalam penelitian ini menggunakan triangulasi sumber dan metode. Analisis data yang dilakukan yakni model analisis maju bertahap menurut Spradley (Spradley, 1997).

\section{Hasil dan Pembahasan}

\section{Integrasi Sosial Beda Agama di Desa Mongan Poula, Mentawai}

Masyarakat Mongan Poula memiliki berbagai macam agama, ada lima agama yang terdapat di Desa Mongan Poula yaitu Kristen Katolik, Islam, Protestan, Bahai dan IFGF. Meskipun berbeda agama, masyarakat disana selalu menjaga hubungan baik antar mereka meskipun ada konflik tetapi mereka bisa menyelesaikan masalah tersebut. Tujuan dari penelitian ini adalah untuk menjelaskan dan mendeskripsikan penyebab masyarakat Desa Mongan Poula mampu hidup rukun. Maka berdasarkan dari penelitian dan observasi yang telah peneliti lakukan didapatkan ada 2 (dua) alasan paling mendasar yaitu nilai adat istiadat sangat kuat, dan persaudaraan atau kekeluargaan sangat kuat di dalam persaudaraan terdapat kerja sama antar mereka di Desa Mongan Poula. Berikut akan dijabarkan secara terperinci:

\section{Nilai Adat Istiadat orang Mentawai}

Hal adat ini berdasarkan hasil wawancara yang peneliti lakukan dengan beberapa informan tentang kehidupan harmonis antar umat agama yang berbeda, yang disampaikan oleh informan Bapak Dajul Sakoan (60 tahun) yaitu:

“...... oto kakai nek marukun lek kai kajek ka langgai ta atak sipagogoluk, anek kakai marukun sampai sinek oto en dulu zaman pusirauken mai atak kakai pagoluk ma aman lek hidup mai karena emat adat mai siburuk siken sampai sikenek masalah arat atak kupermasalah aken kai iya lek en sambek.

\section{Bahasa Indonesia:}

“...Kami di Desa Mongan Poula rukun-rukun saja, tidak ada pertengkaran yang terkait tentang agama, dulu waktu saya muda kami bermasyarakat sangat damai sekali, ada pun konflik- konflik kecil itu masih bisa diselesaikan dengan kepala suku, sudah adat istiadat ataupun sudah kebiasaan kami yang menerapkan penyatuan beda agama".

Dari apa yang disampaikan informan menunjukkan bahwa masyarakat Desa Mongan Poula sejak dulu sampai sekarang hidup rukun karena kuatnya nilai adat istiadat yang masih dipegang dari dahulu sampai sekarang oleh masyarakat Mentawai khususnya di Desa Mongan Poula.

Begitupun yang disampaikan oleh Bapak Adrias Loken (umur 55 Tahun) sebagai berikut:

“...Kakai kajek kalnggai mai ma kuat adat mai sejak dulu ma tentram lek kai walaupun kajek kalanggai mai tak siniai agama tetap ma rukun kai beberen mai, indak sia kasia me mumenggui jen kasia rae ranau aken lonceng atak tugalik loi moi karena ku agai kai emang siken kasia arat ra keleu dulu kaki pusirauken mai siken leu sampai sinek atak kugalak aken kai abe tapun na incak tak an iyagai galak aken en.

\section{Bahasa Indonesia:}

“.... Kami di Desa Mongan Poula tetap menjalin kerukunan dengan baik, menjalin persaudaraaan yang baik dan tidak ada konflik" besar yang menyebabkan tidak adanya permasalahan agama, karena kami menyadari apa pun agamanya kami tetap menjalin persaudaraan yang baik, karena waktu dulu sebelum maju ini Desa Mongan Poula dan belum ada banyak orang dan desanya belum sebagus ini kami dulu menjalin hubungan baik-

Culture \& Society: Journal of Anthropological Research Vol. 2, No. 4, Th. 2021 
baik saja sesama, malahan dengan saudara tetangga, kami memasak makanan di rumah terus kami panggil mereka makan bersama walaupun tetangga itu masak juga tetapi makan bersama disitu terlihat silahturahmi dengan baik padahal agama mereka berbeda dengan agama kami".

Dari hasil wawancara dapat disimpulkan masyarakat Desa Mongan Poula selalu hidup bersama dan selalu berintegrasi antar sesama masyarakat walaupun beda agama, dengan hal seperti itu terlihat jelas masyarakat Desa Mongan Poula seperti itu karena dengan adat istiadat yang sudah tertanam sejak dulu didiri mereka sendiri.

Menurut Teori Gluckman, integrasi sosial yang terjadi di masyarakat Desa Mongan Poula, masyarakat disana selalu menjaga hubungan baik antar sesama walaupun beda agama di dalam satu Desa. Ketika terjadi konflik masyarakat selalu bisa menyelesaikan masalah tersebut dengan hal seperti itu terlihat jelas masyarakat Desa Mongan Poula selalu rukun dan terjadinya integrasi antar sesama beda agama disebabkan karena adanya nilai adat istiadat yang tertanam di diri mereka sejak dulu.

Adat istiadat yang menjadi penyatu masyarakat Mentawai di Mongan Poula walaupun hidup berbeda agama yaitu adat Sittaggigailau dan Pagetsabbau, yang akan dijelaskan di bawah ini.

\section{Nilai Sittaggigailau}

Nilai pemersatu antara roh dan jasad terlihat bahwasanya hubungan manusiaen dengan langit yang menimbulkan keduanya itu disatukan dan setelah disatukan akan berpengaruh ke yang lain yang mereka lakukan dalam dunia mereka tersendiri seperti dapat menyembuhkan orang sakit (Nur, 2019). Maksud dari nilai budaya Sittaggigailau hubungan manusia dengan dengan dunia langit dan dunia hutan yang disebut tai ka manua (Roh langit) dan tai ka leleu (roh hutan) untuk melakukan persembahan yang biasa dilakukan yaitu punen atau pesta inilah membuat orang Mentawai tidak bisa meninggalkan nilai-nilai yang sudah diajarkan oleh nenek moyang terdahulu. Hal ini sesuai yang diungkapkan oleh nenek Paporot Siribatek (70 Tahun) sebagai berikut:

“...Kegiatan pelaksanaan punen atau pesta ketika salah satu dari masyarakat Desa Mongan Poula ada yang melaksanakan pesta maka seluruh masyarakat Desa Mongan Poula ikut partisipasi dalam persiapan acara pesta tersebut mereka ikut gotong-royong bersama seperti kalau ibu-ibu masak-masak kalau laki-laki itu mengambil kayu api, dan kalau untuk remaja ikut mendekorasi tempat pesta. Masih banyak contoh lain di Desa Mongan Poula yang menunjukkan mereka selalu hidup rukun".

Dilihat dari hasil wawanacara dan observasi orang Mentawai selalu mengadakan Punen (upacara) untuk setiap kegiatannya seperti, perkawinan, pembangunan, peresmian rumah, persemian penurunan perahu (Coronose, 1986) sejak dulu sudah dilakukan oleh nenek moyang dulu dan sampai sekarang masih diadakan.

\section{Nilai Pagetsabbau}

Nilai pagetsabbau dianggap sangat penting karena disini dulunya masyarakat Mentawai sangat menyakini kepada hal-hal yang gaib seperti roh atau pun pada hal-hal gaib lainnya seperti bisa meramal nasib, selamat dan bangun dari kematian, menghidupkan kembali binatang yang sudah mati, menumbuhkan kembali pohon yang sudah ditebang, dan mengubah seorang yang jelek menjadi tampan (Coronose, 1986) Menunjukkan bahwa dia dianggap sebagai roh yang melindungi dirinya dan orang lain. Ketika mereka sudah "bedamai" dengan roh atau dunia lain maka mereka akan bisa berdamai dengan orang di sekelilingnya.

Dari kedua nilai tersebut mengandung makna, nilai kepatuhan orang Mentawai terhadap roh dan jiwa, yang melalui persembahan punen. Kepercayaan orang Mentawai kepada roh yang 
melindungi Sikerei. Konsep harmonis orang Mentawai adalah ketika mereka menjaga keseimbangan dan keselarasan antara dunia nyata dan dunia supranatural (Spina, 1981).

Berdasarkan hasil wawancara dengan informan diungkapkan bagaimana masyarakat Mongan Poula dapat bekerja sama, bergotong-royong bersama dengan anggota masyarakat walaupun mereka berbeda agama. Punen yang diadakan oleh warga merupakan bagian mengikat hubungan antara manusia dengan Roh gaib serta dengan manusia dan alam. Hal ini diungkapkan oleh bapak Redwan Sapatandekan (50 Tahun) sebagai berikut.

“...... kakakai kajek pasibetei abak moi sia rarob aken kai dari pas pasibetei sampai alepakan ra rop aken kai kajek atak kasia raagai en tak abak mai tetapi moi leu sia, kakai sebagai tua rumah jen moi kusediakaen kai lok rak kan ra tak te rasuru kai tetapi sadar diri kai emang siken kanak pasibetei sainak, pasiseu manuk pokok na simanam pasisaki ubek ra.

Bahasa Indonesia:

“...Kami disini di Desa Mongan Poula ketika kami membuat sampan, masyarakat datang untuk membantu kami satu suku dan padahal itu tidak ada kami memanggil orang tersebut mereka yang datang sendirinya dan kami sebagai tuan rumah pasti akan menyediakan makanan, atau berburu babi sebagai ucapan terima kasih dan juga untuk punen atau pesta akibat sampan sudah selesai".

Hal ini dijelaskan oleh bapak Kepala Desa Asrul Sani S, Sag mengatakan bahwasanya tanggal 4 April 2021 keluarganya merayakan punen atau pesta keluarga bapak tersebut tidak semuanya Islam ada sebagian yang Katolik tetapi walaupun seperti itu bapak selalu menghargai mereka dan tanpa panggilan dari tuan rumah tersebut, masyarakat Desa Mongan Poula ikut partisipasi dalam memeriahkan acara tersebut. Ibu-ibu ikut masak-masak dan laki laki ikut ambil kayu dan lain sebagainyal. Tata cara dalam pelaksanaan punen tersebut tuan rumah membagi 2 tempat untuk yang beragama Islam dan yang beragama Katolik. Tujuanya supaya saling toleransi dan saling menghargai. Khusus yang beragama Islam mereka ditempatkan tempat yang Islam juga dan lauknya adalah daging Ayam dan yang beragama Katolik diberikan tempat khusus juga dengan lauk daging babi. Terlihat bahwasanya mereka saling toleransi antar sesama walaupun beda agama saling berintegrasi antar mereka.

Dari hasil wawancara dijelaskan bahwasanya ada nilai-nilai adat yang mengajarkan masyarakat Mentawai khususnya Desa Mongan Poula untuk hidup rukun dan terjadi integrasi di desa tersebut karena adat istiadat yang tertanam sejak dulu didiri mereka itu sendiri.

Hal ini dianalisis dengan teori Gluckman yang menyatakan bahwa antara konflik, moral, kepercayaan, agama dan ritual dan apek-aspek kebudayaan inilah yang saling terjalin sehingga konflik yang terjadi dalam masyarakat tidak menghancurkan sistem sosial. Masyarakat Metawai sejak dulu sudah ditanamkan nilai-nilai adat terdahulu supaya bisa menghargai agama lain dan menjalin integrasi antar sesama walaupun beda agama sejak dulu sebelum mengenal agama masih mengenal kepercayaan. Masyarakat Mentawai sudah ditanamkan dalam diri mereka nilai-nilai kebersamaan a dan diterapkan oleh generasi sampai sekarang.

Ada tiga aturan adat Pagetassabbau atau pepatah yang mengharuskan masyarakat Mentawai selalu hidup rukun:

\section{Simakerek Bagatta}

Pepatah ini diartikan dalam bahasa Mentawai yaitu kehidupan bersama, sejak dulu mereka saling menjalin kehidupan bersama baik dalam keluarga mereka maupun orang lain mereka selalu menjunjung tinggi nilai adat atau budaya hingga saat ini masih menerapkan sikap toleransi, sikap saling menghargai antar sesama. Mereka selalu diingatkan dengan pepatah Simakerek Bagatta marilah kita hidup di tengah masyarakat dengan saling menghormati tidak pandang agama mana 
pun yang penting saling menjalin hubungan dengan baik. Hal ini diungkapkan oleh Bapak Geak (67 Tahun) sebagai Berikut:

“...aku nek tateteu sebagai bajak Gereja Katolik kalanggaita jek ma kuat menghormati berbagai perbedaan, tak leu aku nek ikua na sedangkan pemerintah tah nek bupati nta nek Kepulauan Mentawai siken leu kakaya iyajaraken ita setiap indak iya paruruk ka umum pokokna tak tukalipeu iya ikua na nek pokok na ita saraina beberenta jek keluarga ita anek iya kakaya nek Katolik, Islam, Baha"I jen beberen agama ka langgaita tetap leu ita nek bersaudara bak ta beda aken na. Kalulun siburuk tateteu ta ma rukun sia oto kaita sinek leu tak leu tagalak aken. iya en ikua bupati nta sampai sinek nak kaku mupidato aku nek ka Gereja tak tukalipeu kukua na".

“...Bapak selaku bajak Gereja atau yang menjadi pemimpin Gereja Katolik bapak sudah menanamkan di umat agama Katolik sejak dulu sampai sekarang karena sudah dituakan sebagai pemimpin agama bapak atau dikatakan kalau dalam Islam Ustadz. Setiap Bapak berpidato di Gereja pas hari minggu bapak selalu mengucapkan pepatah yang diajarkan sejak dulu oleh nenek moyang atau dikatakan sudah adat, disitu terlihat bahwasanya kita satu dan kita adalah keluarga apa pun agama mu kita tetap menghargai dan juga di Mentawai tidak ada larangan agama bebas mau milih agama yang diyakini intinya kita tetap bersaudara".

Dari hasil kesimpulan wawancara tersebut terlihat jelas pepatah yang disebut Simakerek Bagattta atau kehidupan bersama selalu mereka tanamkan di diri mereka sejak dulu hingga sampai sekarang.

\section{Kapuaranan Simaeruk}

Artinya adalah saling menghargai antar sesama seperti yang telah diajarkan oleh nenek moyang dan sampai sekarang ini masih diterapkan dengan adanya hubungan baik, tentram, damai, rukun walaupun berbeda keyakinan.

Aturan yang dibuat sejak dulu sampai sekarang masih berlaku dan ketika mereka melanggar maka akan ada sanksi (denda) (Herman, 1979). Mereka selalu diajarkan sejak kecil oleh keluarga untuk hidup damai, selalu mengikuti aturan dimana aturan tersebut untuk kebaikan kita bersama. Di dalam agama diajarkan untuk selalu hidup bertoleransi antar sesama, saling menghargai, setiap agama tidak boleh membeda-bedakan agama lain. Ada salah satu informan mengatakan bahwa kerukunan di Desa Mongan Poula sampai saat ini sudah terbiasa dengan perbedaan agama malahan di dalam satu keluarga menganut dua agama tetapi itu tidak menjadi persoalan bagi mereka. Hal ini diungkapkan oleh Bapak Abias Sakoan (55 tahun) sebagai berikut:

“...anen siken kalanggai ta nek ma hidup rukun reu ku nek murimanua perbedaan keyakinanan atau arat mai en mabeda jek agama mabiasangan kai, abekia en siburuk nenek teteu siburuk ma aman lek sia oto nek arajarken ita nek bawasannya harus saling maeruk patuan antar sesama jek kalanggai".

Bahasa Indonesia:

“...Bapak sebagai kepala suku Sakoan di Desa Mongan Poula sangat terbiasa sekali dengan adanya kerukunan yang baik antar mereka yang berbeda keyakinan. Dulu waktu nenek moyang belum mengenal agama, dulu agama nenek moyang Arat Sabulungan ketika mereka dulu belum ada tempat tinggal yang pada saat sekarang ini. Dalam satu suku mereka punya uma yang dimana uma tersebut dinding uma terbuat dari kulit kayu (Karoi), terbuat dari bahan rotan, kayu bulat dibawah uma tersebut atau teras itu ditempati kandang babi. Nah di Uma itu tempat pemersatu semua anggota keluarga sesama suku. Walupun mereka banyak tetapi mereka selalu kerja sama atau saling menghargai antar sesame". 
Dari hasil wawancara dapat disimpulkan masyarakat Mentawai disatukan di dalam uma atau di dalam satu rumah dalam satu suku mereka sudah terbiasa menjaga silaturahmi antar sesama sehingga terjadi integrasi sosial di masyarakat Mentawai.

\title{
Bui Ibara Lagat Bagatta Samba Musara Lek Sita Kasimaeruk
}

Maksud dari pepatah tersebut jangan ada konflik antar sesama marilah kita sama-sama membina dalam kerukunan sebab kita adalah satu dan kita adalah keluarga, disini sudah terlihat jelas sekali pada zaman dulu orang Mentawai sudah diajarkan dengan nilai-nilai yang membuat masyarakat bisa hidup rukun selalu berdampingan dan menghargai agama lain. Pepatah ini selalu diutarakan ketika berpidato di hari hari besar (Kurniawan \& Pendahuluan, 2018). Hal yang diungkapkan oleh Bapak Oskar Sakoan (69 Tahun ) sebagai berikut:

\begin{abstract}
“...Oto kaku siagai ku selama aku nek murimanua anek an rura ku 65 tahun atak te kakai kajek nek pagoluk sabeu menurut arat mai, dulu kakai indak peu aku sirauken indak kai mupenen te seluruh langgai ka Mongan Poula moi rarop aken kai kejek nek mupunen elek mutalimeu kai oto kakai nek emang arat mai kajek ruruk en dulu leu sateteu mai siken leu indak leu en pagoluk taleu siken tak leu mapalik palingan korok lek iya peu en iyagai peu kai musyawarah bersama. "Bui Ibara Lagat Bagatta Samba Musara Lek Sita Kasimaeruk" artinya jangan ada konflik antar sesama marilah kita sama sama membina dalam kerukunan atau sebab kita adalah satu dan kita adalah keluarga".
\end{abstract}

Bahasa Indonesia:

“...Selama bapak hidup sekarang udah umur bapak udah masuk 65 tahun termasuk lama disini bapak tinggal di Desa Mongan Poula menurut bapak masyarakat disini mereka menjalin keharmonisan yang baik interaksi sangat bagus tidak ada konflik'besar tentang agama yang terjadi di Mongan Poula itu pun ada hanya permasalahan kecil saja dan bisa diselesaikan secara bersama dengan kepala suku namanya tinggal di Desa pasti ada masalah yang terjadi, tetapi itu bisa diselesaikan tidak sampai berminggu minggu masalah tersebut, yang kami jalani saat sekarang sudah kebiasaan dulu ataupun adat budaya kuat tidak bisa ditinggalkan ada pepatah Mentawai yang mengajarkan kita harus hidup berdampingan "Bui Ibara Lagat Bagatta Samba Musara Lek Sita Kasimaeruk" artinya jangan ada konflik antar sesama marilah kita sama sama membina dalam kerukunan atau sebab kita adalah satu dan kita adalah keluarga".

Dari apa yang disampaikan oleh informan kerukunan yang baik terjadi antar umat beragama itu memang sudah kebudayaan ataupun adat istiadat yang tidak bisa ditinggalkan karena orang Mentawai menyadari kerukuann itu sangat penting bagi masyarakat. Orang Mentawai di desa Mongan Poula sangat rukun bukan saat ini saja mereka rukun tetapi dulunya masyarakat Mentawai selalu berpatokan pada pepatah yaitu "Bui Ibara Lagat Bagatta Samba Musara Lek Sita Kasimaeruk" artinya jangan ada konflik antar sesama marilah kita sama sama membina dalam kerukunan atau sebab kita adalah satu dan kita adalah keluarga. Pepatah ini merupakan ajaran dulu atau kebiasaan teteu teu siburuk (nenek kakek zaman dulu) mereka selalu menanamkan kerja sama atau hidup berdampingan dengan sesama mereka walaupun berbeda keyakinan atau agama, karena dulunya masyarakat Desa Mongan Poula agamanya adalah arat sabulungan sebelum mempunyai agama yang sekarang ini.

Nilai budaya berupa Adat istiadat simakrek bagatta, Kapuaranan Simaeruk, dan Bui Ibara Laggat Bagatta Samba Musara Lek Sita Kasimaeruk adalah akar kehidupan bersama mereka orang mentawai yang tidak bisa mereka lupakan. Pepatah tersebut tidak hanya sebuah pepatah akan tetapi menjadi falsafah hidup bagi masyarakat mentawai karena sudah menjadi tradisi mereka seperti itu dan hingga sekarang walaupun beda agama mereka selalu hidup damai. Kaitan dari teori Gluckman adalah membahas bagaimana masyarakat Desa Mongan Poula terjadinya integrasi sosial antar mereka walaupun beda agama karena disebabkan nilai adat istiadat yang 
menjadi pedoman dalam bertingkah laku, orang mentawai saling berhubungan baik dengan sesama walaupun beda agama.

\section{Persaudaraan yang kuat}

Persaudaraan adalah perasaan simpati juga empati yang mengikat dua orang ataupun lebih dalam suatu hubungan yang tidak selalu berdasarkan keterkaitan darah tetapi juga karena akidah, karena sama-sama mahkluk Tuhan, satu bangsa yang sama dan lain sebagainya. Persaudaraan di Desa Mongan Poula sangat kuat sekali karena nenek moyang mengajarkan untuk menjalin persaudaraan yang baik, mereka sudah terbiasa dengan hidup bersama dan hingga saat ini sekarang masih menanamkan nilai keluarga yang kuat. Hal ini diungkapkan oleh nenek Sok Sok (65 tahun) sebagai berikut:

“...kaku jek dulu tak orang jek aku langgai ku sasareu lek ka palembang atak kaku ku agai nek mentawai kukua lek padang kepek amoi aku kajek tak maramai sirimanua malain kakota kaku nek agama ku Islam te tak peu ku agai kaku nek bahasa mentawai waktu aku kajek amoi tak peu mareu aku kajek masyarakat kejek ra obak aku atak ra erei aku padahal agama ku teen islam oto kaku malotok aku iya en oni na persaudaraan ra kajek maeruk mujalan mamulus lek".

Bahasa Indonesia:

“...Dulu Ibu ini pendatang dari luar bukan orang Mentawai asli sebelum datang ke sini ibu tidak tau daerah Mentawai ibu kira Kota Padang, sampai ibu di Desa Mongan Poula penduduknya sangat sedikit dan ibu lihat secara pribadi mereka hidup rukun, permasalahan kecil masih bisa diselesaikan tetapi kalau permasalahan besar yang mengangkut agama tidak ada selama ibu tinggal di Desa Mongan Poula sampai punya suami di sini. Malahan keluarga suami ibu itu ada yang beragama Baha"I tetapi keluarga ibu tidak mempermasalahkan karena itu kan saudara mereka sendiri tidak perlu dipermasalahkan lagi".

Dari hasil wawancara terlihat masyarakat Mongan Poula selalu hidup berintegrasi antar sesama mereka karena adanya persaudaraan yang kuat antar mereka, sudah menganggap mereka adalah saudara walaupun terjadi konflik masyarakat disana bisa mengatasinya dengan baik dan bijaksana.

Hal ini dianalisis dengan teori Gluckman masyarakat Desa Mongan Poula menjalin kerukunan dengan baik antar sesama mereka walaupun beda agama dan disini tercipta integrasi sosial masyarakat Desa Mongan Poula, saling bekerja sama, saling membantu antar mereka, menciptakan kedamaian walaupun ada konflik tetapi dengan adanya konflik tidak membuat mereka terpecah justru konflik membuat mereka satu. Dengan adanya konflik mereka bisa menyelesaikan masalah itu sendiri atau dibantu dengan kepala suku atau pabalai. Terlihat jelas bahwasanya integrasi sosial mereka sangat kuat dengan terciptanya seperti hidup rukun itu karena ada nilai adat terdahulu yang mengharuskan mereka selalu hidup rukun antar sesama mereka walaupun beda agama dan ini sudah tertanam di dalam diri mereka sampai sekarang. Konflik besar tidak terjadi di Mentawai berkaitan beda agamadan adapun konflik kecil bisa diselesaikan secara bersama.

\section{Kesimpulan}

Berdasarkan hasil penelitian diketahui faktor penyebab masyarakat mampu hidup rukun di Desa Mongan Poula Kecamatan Siberut Utara Kabupaten Kepulauan Mentawai diantaranya adalah 1) karena adanya istiadat, sehingga masyarakat Mongan Poula mampu hidup rukun selalu menjalin hubungan baik antar mereka walaupun berbeda keyakinan dan juga nilai-nilai adat sudah diajarkan oleh nenek moyang terdahulu orang Mentawai, nilai-nilai yang bermakna dari adat istiadat yang telah diajarkan nenek moyang terdahulu yaitu ada nilai ada 2 nilai adat yang

Culture \& Society: Journal of Anthropological Research Vol. 2, No. 4, Th. 2021 
mengandung kerukunan atau menjalin kebersamaan antar sesama yaitu, Nilai Sitangingailau dan nilai Pagetsabbau . Dari kedua nilai tersebut mengandung makna, nilai kepatuhan terhadap orang Mentawai, roh dan jiwa yang melalui persembahan sewaktu punen, kepercayaan orang Mentawai kepada roh yang melindungi sikerei, konsep harmonis yang membuat orang Mentawai adalah ketika mereka menjaga keseimbangan dan keselarasan antara dunia nyata dan dunia supranatural 2) Persaudaraan yang kuat dalam keluarga dan masyarakat, yang disadari oleh masyarakat yang berakat kepada adat istiadat Mentawai untuk hidup rukun dan damai.

\section{Daftar Pustaka}

Abidin, Z., \& Yusuf, Y. (2014). Pengantar Sistem Sosial Budaya Indonesia. Bandung: CV Pustaka Seni.

Coronose, S. (1986). Kebudayaan Suku Mentawai. Jakarta: Grafidian Jaya.

Harton, P. B. (1984). Sosiologi. Jakarta: Erlangga.

Herman, S. (1979). Mentawai. Jakarta: Pradnya Paramita.

Kurniawan, R., \& Pendahuluan, A. (2018). Harmonisasi Masyarakat Mentawai. Al-Qalb: Jurnal Psikologi Islam, 9(2), 111-118.

Muslich, A. (2013). Konflik Dan Integrasi Sosial. Muaddib, 3(1), 1-12.

Nur, M. (2019). Sikerei dalam Cerita: Penelurusuran Identitas Budaya Mentawai. Jurnal Masyarakat Dan Budaya, 21(1), 89-102.

Saputri, V. S. D. (2019). Intekrasi Sosial Umat Islam Dan Umat Kristen Pantekosta Di Desa Suro Kecamatan Kalibagor Kabupaten Bayumas. IAIN Purwokerto.

Spradley, J. P. (1997). Metode Etnografi. Yogyakarta: Grafidian Jaya.

Sutomo, P. (2017). Penggunaan Smartphone Terhadap Proses dan Efektivitas Belajar Mahasiswa Pendidikan Akuntansi FKIP. Jurnal Sains Dan Seni ITS, 6(1), 51-66.

Wijayanti, R. (2019). Kerukunan Antar Umat Beragama Di Desa Gebangsari Kecamatan Klirong Kabupaten Kebumen. Universitas Negeri Semarang. 